\title{
Embarking on quality improvement in anaesthetic practice
}

\author{
Anuja Abayadeera $^{I^{*}}$, Gitanjali Jayatilaka \\ Professor in Anaesthesiology ${ }^{1 *}$, Faculty of Medicine, University of Colombo, Sri Lanka. Consultant \\ Anaesthetist ${ }^{2}$, Asiri Surgical Hospital, Colombo, Sri Lanka.
}

We as anaesthetists take a lead role in service provision and are members of multidisciplinary teams. Our focus in training, education and practice is patient safety and delivery of quality care. In order to achieve these, we are getting used to or are using check lists, bundles, processes etc. These concepts arise from Improvement Science. ${ }^{1}$ Though relatively new to us this science has been used in industry especially by motor car manufacturers, agriculture and aviation and has proven to be a robust statistical science.

Does quality improvement (QI) differ from research and audit? Research is about finding new knowledge and involves inclusion and exclusion criteria. Its application to the general population needs completion of the research. Audit looks at whether we are reaching required or set targets and is often retrospective, and occasional. Unless an audit cycle is completed, it is of no value. Improvement Science looks at improving the processes of a system. Quality improvement is a continuous activity, and collection of data is always prospective.

What is quality in relation to healthcare? The Institute of Medicine ${ }^{1}$ describes quality in healthcare as being safe, effective, patient centered, timely, efficient and equitable. Quality improvement is broadly described as the systematic use of a range of tools and techniques to improve patient care and associated healthcare processes on a continuous basis.

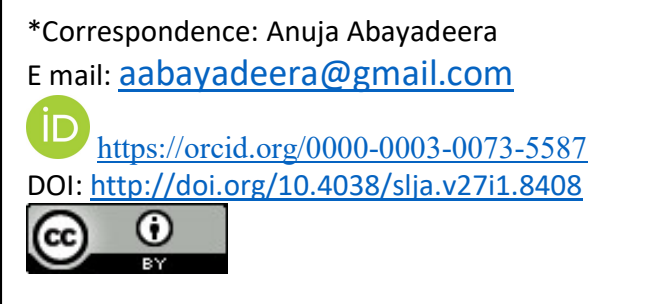

It is a continuous and unending effort by all involved- healthcare personnel, patients and their families, researchers, planners, educators to make changes that will result in better patient outcome, better performance of a system and better professional education.

How do we embark on a quality improvement project? Once an audit is done or a patient experience is known, and problems are identified in a given system, a change needs to occur in this system to show an improvement in quality. To achieve a change there needs to be a "will" to change the system, "ideas" to change it and the "skills" to execute the change.

Therefore, the first step is to find what we want to improve. We can obtain ideas for quality improvement projects in anaesthetic or critical care practice through NICE guidance, audit reports from Colleges of Anaesthesiologists of other countries and the World Federation of Societies of Anaesthesiologists.

\section{Model for Improvement}

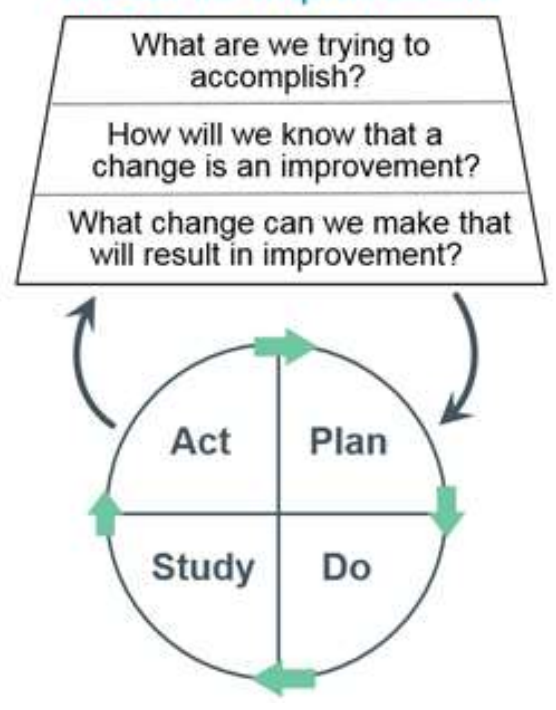


The model for improvement ${ }^{2}$ is the basic tool used in Improvement Science and in organising quality improvement projects. It is developed by the Associates in Process improvement. This method uses small and frequent samples to drive a change in a faster and more proactive manner.

It is also important to get the 'right' people involved from the start. It is important to identify the problem well before embarking on solutions possible. The changes made should be small, reversible, and tested in a defined location or population. Data collected should be just adequate and where possible try to collect existing data.

For us the initial focus should be on training in QI skills. Teaching and training in QI methodology is a part of the core curriculum for undergraduates and postgraduates in many countries. QI is now mandatory for junior doctors in UK, who are required to conduct one quality improvement project and to use the results to improve patient care.

Quality improvement in patient care depends on understanding the complex systems involved. It is everyone's responsibility and the time to start is now.

\section{References}

1. Rooney KD. The science and history of improvement. In: Pedan C, ed. Quality improvement in Anaesthesia. $3^{\text {rd }}$ edition, Royal College of Anaesthetists Raising the Standard: a compendium of audit recipes, 2012, pg 23-24.

2. Langley G, Moen RD, Nolan KM, Nolan TW, Norman CL, Provost LP. The improvement guide: a practical approach to enhancing organizational performance. San Francisco: JosseyeBoss;2009. p. 512 